\title{
Mensuração e Análise do Perfil Empreendedor dos Egressos de Ciências Contábeis
}

\author{
Alex Eckert ${ }^{1}$ \\ Marlei Salete Mecca ${ }^{2}$ \\ Micheli Gasperin Eckert ${ }^{3}$
}

\begin{abstract}
Resumo
A economia dos países depende basicamente das empresas instaladas em seus territórios. Para que estas empresas sejam criadas, existe a necessidade da figura do empreendedor que inicie este novo negócio. O que se percebe é que muitas empresas não sobrevivem por inúmeros motivos, e um deles é a falta de conhecimento sobre a gestão do negócio. Os cursos de graduação podem, além de despertar o perfil empreendedor nos indivíduos, auxiliar estes futuros empreendedores no sentido de capacitá-los na gestão do negócio. Assim, o objetivo desta pesquisa é identificar o perfil empreendedor dos egressos do curso de Ciências Contábeis de uma instituição de ensino superior privada. Para alcançar este objetivo, foi distribuído um questionário elaborado e validado por Demac (1990), composto de questões objetivas, aos formandos do referido curso. Os resultados apontam que a grande maioria dos pesquisados não tem perfil empreendedor, e o restante são empreendedores incipientes, potenciais e latentes.
\end{abstract}

Palavras-chave: empreendedorismo; perfil empreendedor; gestão; ciências contábeis.

\section{Measurement And Analysis Of The Entrepreneur Profile Of Accounting Students}

\begin{abstract}
The economy of the country depends primarily on companies located in their territories. For the creation of these companies, its necessary an entrepreneur to start this new business. What is noticeable is that many companies do not survive for many reasons, and one of them is the lack of knowledge in business management. Undergraduate courses may also awaken the entrepreneurial profile in individuals, help these future entrepreneurs in order to empower them in managing the business. The objective of this research is to identify the entrepreneurial profile of students who graduated from Accounting for a private institution of higher education. To achieve this goal, we distributed a questionnaire developed and validated by Demac (1990), composed of objective questions, to the graduates of that course. The results show that the vast majority of respondents do not have entrepreneurial, and the rest are fledgling entrepreneurs, potential and latent.
\end{abstract}

Keywords: entrepreneurship; entrepreneurial profile, management, accounting sciences.

\footnotetext{
${ }^{1}$ Doutor em Administração - UCS/PUCRS. Professor da Universidade de Caxias do Sul - UCS Caxias do Sul/RS - Brasil. alex.eckert@ bol.com.br

${ }^{2}$ Doutora em Engenharia da Produção - UFSC. Professora da Universidade de Caxias do Sul - UCS Caxias do Sul/RS - Brasil. msmecca@gmail.com

${ }^{3}$ Especialista em Controladoria - UCS. Bacharel pela Universidade de Caxias do Sul - UCS Caxias do Sul/RS - Brasil. mgasperin@ hotmail.com
} 


\section{Introdução}

O incremento econômico de um país depende basicamente das empresas, que com suas atividades industriais, comerciais e de prestação de serviços contribuem para a movimentação da economia, pois geram empregos e renda (GLAESER; KERR; KERR, 2015). A criação dessas empresas está fortemente ligada ao empreendedorismo, e, quanto mais ele estiver presente em um país, maior será o seu desenvolvimento econômico (DOLABELA, 1999). Uma boa parte dessas empresas é composta de grandes grupos, muitas delas até originárias de outros países, as chamadas multinacionais. Outras, menos complexas, mas nem por isso menores em tamanho, são genuinamente nacionais. Estas empresas, em sua grande maioria, são sucessoras do que já foi uma pequena ou média empresa, que, concebidas e geridas de maneira adequada, se criaram no mercado, sobreviveram e se desenvolveram. De acordo com os dados da pesquisa realizada em 2010 pelo GEM (Global Entrepreneurship Monitor), o Brasil é o segundo país mais empreendedor, perdendo apenas para a China (GEM, 2010).

Para que estas pequenas empresas sejam criadas, existe a necessidade de que haja um empreendedor, aquela pessoa de visão de mercado e desbravadora que inicie este novo negócio. Ser um empreendedor de sucesso é o sonho de muitas pessoas. No entanto, o que se percebe é que muitas empresas não sobrevivem aos primeiros anos de atividade. Segundo dados do SEBRAE, em pesquisa realizada no estado de São Paulo durante doze anos (1997 a 2009), 50\% das empresas abertas não concluem o quarto ano de atividade e $58 \%$ encerram suas atividades antes mesmo de completar seis anos (SEBRAE, 2011).

Essa mesma pesquisa apontou alguns motivos para o insucesso das empresas em seus primeiros anos de vida, onde merecem destaque a ausência de comportamento empreendedor, ausência de planejamento, deficiências no processo de gestão empresarial, dificuldades com a conjuntura econômica, impacto dos problemas pessoais sobre o negócio e insuficiência de políticas públicas de apoio aos pequenos negócios (SEBRAE, 2011).

Diante dos problemas abordados, verifica-se que alguns estão relacionados ao contexto econômico nacional, como por exemplo, a situação da ausência de políticas públicas, sobre o qual o empreendedor pouco ou nada pode interferir. No entanto, existem outros, como por exemplo, a ausência de planejamento e as deficiências dos empreendedores na gestão do seu negócio, que dependem exclusivamente do empreendedor. Obter uma formação específica no seu ramo de negócio, além de um curso de graduação, já seria para o empreendedor um grande reforço para o sucesso do seu negócio. Stevenson (2001) acredita que as universidades 
têm um papel fundamental na formação de futuros empreendedores, visto que uma teoria cada vez mais aceita é a de que o espírito empreendedor dos indivíduos pode ser desenvolvido com base na potencialização de algumas habilidades pré-existentes e na melhoria de novas habilidades.

Ainda com base nos problemas apresentados que se referem a gestão do empreendimento, é possível afirmar que profissional formado em Ciências Contábeis tem uma formação que o prepara para auxiliar o empreendedor, pois o referido curso aborda, em suas disciplinas, a base teórica necessária para tal. Além disso, é cada vez mais freqüente no Brasil a inclusão de disciplinas específicas de empreendedorismo nos projetos pedagógicos desse curso, numa tentativa de fazer com que os egressos de Ciências Contábeis também se transformem em empreendedores.

Assim, a questão que fica a ser respondida é se todos estes subsídios fornecidos nos cursos despertam um perfil empreendedor nestes profissionais de contabilidade que estão saindo das faculdades e universidades. Diante do exposto, o objetivo geral deste trabalho é identificar o perfil empreendedor dos egressos do curso de ciências contábeis da Universidade de Caxias do Sul, na Cidade Universitária (Campus Sede).

\section{Empreendedorismo e processo empreendedor}

De acordo com Hisrich e Peters (2004) o empreendedorismo é o processo de gerar riqueza. A riqueza é criada por indivíduos que assumem riscos em termos de patrimônio, tempo ou comprometimento com a carreira ou que fornecem valor para algum produto ou serviço. O produto ou serviço pode ou não ser novo ou único, mas o valor deve de algum modo ser difundido pelo empreendedor ao receber e localizar as habilidades e os recursos necessários. Dolabela (1999) complementa afirmando que o empreendedorismo serve para indicar estudos referentes ao empreendedor, incluindo seus perfis, suas atividades, sua área de atuação e suas origens. Levando-se isso em conta, é possível entender melhor o que é um empreendedor e qual o seu perfil.

Para Inácio Jr. e Gimenez (2002), o empreendedorismo é um processo complexo e multifacetado, no qual as variáveis sociais (mobilidade social, cultura, sociedade), econômicas (incentivos de mercado, políticas públicas, capital de risco) e psicológicas influenciam o ato de empreender. Dentre as diversas características do empreendedor, as que mais se destacam são: necessidade de realização, propensão ao risco, criatividade, visão, alta energia, postura estratégica e autoconfiança. Esses mesmos autores abordam o empreendedorismo definindo-o como a busca por resultado tangível ou intangível de uma 
pessoa com habilidades criativas, o qual constitui uma complexa função de experiências de vida, oportunidades, habilidades e capacidades individuais. No exercício do empreendedorismo, é inerente a variável risco em toda a carreira empreendedora.

Para Filion (1999), a literatura em torno do empreendedorismo traz à tona certa confusão de conceitos, visto que alguns estudiosos tendem a direcionar para suas próprias disciplinas. O autor acima cita como exemplo os economistas e os comportamentalistas. Enquanto os primeiros associam o empreendedorismo com a inovação, os outros se concentram em aspectos criativos e intuitivos.

Na visão de Kumar e Ali (2010) o empreendedorismo diz respeito à descoberta de oportunidades lucrativas e a decisão de explorá-los, em perceber uma oportunidade onde os outros vêem apenas contradições, caos e confusão. O processo empreendedor avança quando o empreendedor traz à tona suas qualidades de liderança, pois o sucesso de qualquer empreendimento empresarial envolve a construção de uma equipe com habilidades complementares e talentos, além de uma capacidade para trabalhar como uma equipe.

A sucessão de eventos e mudanças que determina o surgimento da atividade empreendedora é o que a literatura chama de processo empreendedor. Trata-se de um processo holístico e dinâmico, iniciado por um ato humano de vontade própria, que ocorre ao nível da empresa individual, envolve mudança de estado, inúmeras variáveis antecedentes e a descontinuidade, e gera saídas que são extremamente sensíveis as condições iniciais destas variáveis. Em suma, é um conjunto de etapas e eventos que se sucedem, compostos basicamente em quatro estágios: a idéia ou concepção do negócio, o evento que desencadeia as operações, implementação e crescimento (BYGRAVE, 2004).

Segundo Degeorge e Fayolle (2011), o processo empreendedor é um fenômeno complexo, no qual é praticamente impossível determinar uma única causa que faz desencadear o processo. Os estudiosos complementam que vários fatores estão interrelacionados e que, a partir do momento em que o processo empreendedor é disparado, o plano de carreira empresarial deve corresponder às aspirações do indivíduo, e este deve sentirse capaz de ver o projeto até a conclusão.

\section{O Empreendedor e suas características}

Para Bruyat e Julien (2000), empreendedor é alguém que constrói uma visão, com o objetivo de gerar crescimento e lucro, alguém que possui postura estratégica e um comportamento inovador. O empreendedorismo, por sua vez, é resultante do movimento de indivíduos empreendedores. 
É natural que os riscos do empreendedor não ser bem sucedido existem. No entanto, se ele pelo menos for moderadamente bem-sucedido, os retornos devem ser mais que suficientes para compensar qualquer risco que possa haver. Assim, é de se esperar que o empreendimento seja uma atividade consideravelmente menos arriscada que a otimização. Na teoria, a atividade empreendedora deve ser menos arriscada, e não a alternativa mais arriscada (DRUCKER, 1986).

Freqüentemente associa-se o empreendedor à criatividade, mas isso nem sempre ocorre. Muitas vezes é a necessidade ou uma cultura empreendedora inserida em determinada circunstância que leva o empreendedor potencial a desenvolver a sua criatividade. O potencial criativo já existia, mas foi o contexto que estimulou o seu surgimento e, freqüentemente, isso ocorre quando a pessoa ainda é jovem. Quando isso acontece, o jovem desenvolve este potencial e aprende aos poucos a tirar melhor proveito dele (IEL, 2000).

Ao acompanhar-se a trajetória de vários empreendedores, ficou claro que, para alcançar o sucesso, estes tiveram que aprender a dominar melhor as competências adquiridas em cada um dos estágios da evolução de seu sistema de atividades, e estes sistemas de atividades variam de acordo com as diferentes categorias e tipos. $\mathrm{O}$ empreendedor é, com frequiência, considerado uma pessoa que sabe identificar as oportunidades de negócios, os nichos de mercado e que sabe se organizar para progredir (IEL, 2000), e apresenta características comportamentais como otimismo, liderança, iniciativa, confiança e criatividade, dentre outras (FILION, 1999).

Os empreendedores são os agentes de mudança na economia, servindo a novos mercados ou criando novos meios para fazer as coisas, e eles movem a economia para frente. O empreendedorismo está fortemente associado com a inovação (SCHUMPETER, 1982). Para Gerber (1996, p.31), "a personalidade empreendedora transforma a condição mais insignificante numa excepcional oportunidade. $\mathrm{O}$ empreendedor é o visionário dentro de nós. $\mathrm{O}$ sonhador. A energia por trás de toda atividade humana. A imaginação que acende o fogo do futuro". Segundo o mesmo autor, nos negócios o empreendedor é o inovador, o grande estrategista, o criador de novos métodos para penetrar ou criar novos mercados, o gigante dominador de mundos. O empreendedor é a personalidade criativa, que está sempre lidando melhor com o desconhecido, desbravando o futuro, transformando possibilidades em probabilidades.

Timmons (1994) afirma que o empreendedor tenta entender seu ambiente com o intuito de controlar as variáveis para que o seu negócio dê certo e somente assume riscos previamente calculados. Durante todas as etapas do processo empreendedor é perceptível a 
interação do indivíduo com o ambiente, sendo que o contexto, as aspirações e as características pessoais do dirigente têm grande influência sobre ele e suas atividades ao longo do processo empreendedor.

Outros autores trazem estudos acerca do conceito de empreendedor. Por exemplo, Bolton e Thompson (2000) definem o empreendedor como a pessoa que habitualmente cria e inova com o objetivo de construir algo de reconhecido valor, a partir da exploração de oportunidades que identificou a sua volta. Já Leite (1998) tem uma perspectiva mercadológica sobre o empreendedor, definindo-o como alguém capaz de identificar oportunidades de mercado e que possui uma sensibilidade financeira e de negócios para atender seus futuros consumidores e para satisfazer suas próprias necessidades de realização profissional.

\section{O processo de gestão e a contabilidade}

Para que um empreendimento possa estar sempre atualizado e competitivo no mercado, é necessário que o empreendedor faça uma gestão adequada no seu negócio. Segundo Catelli (2001, p.57), “a gestão caracteriza-se pela atuação em nível interno da empresa que procura otimizar as relações recursos-produtos/serviços, considerando as variáveis dos ambientes externo e interno que impactam as atividades da empresa, em seus aspectos operacionais, financeiros, econômicos e patrimoniais”. De maneira resumida, é necessário que o empreendedor esteja sempre atento às modificações que ocorrem no ambiente interno e externo da sua empresa, visto que são diversas as variáveis que atuam diretamente e indiretamente na modificação do seu patrimônio.

Conforme Hong (2009), gestão de negócio é o conjunto de atividades que objetiva entender e explicar como as transações ocorridas ou a ocorrer, no âmbito de um negócio, produzem alterações no seu patrimônio. O conjunto de atividades que forma a gestão de negócio abrange também a prática de fornecer ao gerente recomendações para que as transações produzam resultados mais favoráveis. A avaliação é sempre feita visando o efeito dessas ações no patrimônio.

A gestão deve conduzir a empresa na identificação as oportunidades e ameaças que possam vir a ocorrer. Uma ferramenta que auxilia os empreendedores na definição, planejamento e administração do negócio, é o modelo de gestão. Conforme Perez Jr., Pestana e Franco (1995), é através do modelo de gestão que se pode identificar os diversos aspectos que compõem uma organização. A partir dele é possível determinar o motivo da existência do negócio, bem como auxiliar a sua eficiência e eficácia, garantindo, assim, a sua existência contínua no mercado. Para um melhor entendimento, os autores trazem a definição do que é 
eficiência e eficácia. Eficiência é realizar uma determinada atividade da melhor maneira possível, reduzindo custos e resolvendo os problemas. Eficácia é o grau em que se satisfazem as expectativas previamente determinadas de resultado, atingindo as metas estipuladas e aumentando os lucros.

A contabilidade, por sua vez, estuda sob que condições os fenômenos patrimoniais das aziendas ocorrem, com a finalidade fundamental de proporcionar conhecimentos aos gestores, para que estes sejam eficazes e satisfaçam as necessidades dos empreendimentos (SÁ, 2007). Iudícibus e Marion (1999), por sua vez, afirmam que a Contabilidade é uma ciência social, pois são as ações humanas que formam e modificam o patrimônio, e, para exercer a sua função, ela utiliza a matemática e a estatística como suas principais ferramentas.

De acordo com Ribeiro (2005), a contabilidade é uma ciência social que tem por objeto o patrimônio das entidades econômico-administrativas, e seu objetivo principal é controlar o patrimônio dessas entidades em decorrência de suas variações, para facilitar as tomadas de decisões por parte dos seus usuários. Na contabilidade, segundo Eckert (2013), as informações de ordem econômica dizem respeito à movimentação das compras e vendas, das despesas e receitas, evidenciando os lucros ou os prejuízos apurados nas transações realizadas pela empresa. Já as informações de ordem financeira referem-se basicamente ao fluxo de caixa, que vem a ser as entradas e saídas de dinheiro.

O surgimento da contabilidade gerencial, voltado para a gestão do empreendimento, foi impulsionado pelo aumento da complexidade dos processos de produção. Quanto mais complexo ia ficando a atividade da empresa, mais a contabilidade tinha que ser utilizada para a tomada de decisões. A contabilidade gerencial é responsável pela mudança do foco da contabilidade. Antes do surgimento da contabilidade gerencial, a contabilidade (tradicional) era vista como uma ferramenta que apenas registrava e analisava as informações financeiras. Com o surgimento do ramo gerencial, ela passou a ser vista como uma ferramenta importante para a tomada de decisões, já que se utiliza das informações para modificar o futuro da empresa. Se antes a contabilidade era utilizada apenas para demonstrar as modificações patrimoniais que haviam ocorrido na empresa em um determinado período, depois da criação da contabilidade gerencial ela passou a ser uma ferramenta responsável pelo auxílio nas tomadas de decisão (PADOVEZE, 2009; IUDÍCIBUS, 1998).

\section{O empreendedorismo na formação do Bacharel em Ciências Contábeis}

Segundo Dornelas (2002), proporcionar aos indivíduos educação específica voltada ao empreendedorismo já é uma realidade em escolas e universidades brasileiras. Ele defende que 
qualquer indivíduo pode aprender o que é ser um empreendedor de sucesso. Segundo Bae et al. (2014), evidências apontam que existe correlação entre educação empreendedora e a intenção efetiva de empreender.

Ocorre que, desde sua concepção, muitas instituições de ensino estiveram mais preocupadas em formar profissionais que pudessem atuar nas empresas, como funcionários empregados, do que em formar empreendedores. A crise dos empregos que assolou o Brasil a partir da década de 80 iniciou um movimento em torno do empreendedorismo, quando os pesquisadores perceberam que seria necessário formar um profissional que fosse capaz não só de dar conta da sua área especifica de atuação, mas que soubesse também como gerar seu próprio trabalho. Era necessário transformar o conhecimento que está na universidade em produto ou serviço (CUNHA; STEINER NETO, 2005).

A Resolução CNE/CES nº 10/2004, que institui as Diretrizes Curriculares Nacionais para o Curso de Graduação em Ciências Contábeis, em seu Art. $3^{\circ}$, estabelece que o referido curso deve ensejar condições para que o futuro contador seja capacitado a compreender as questões científicas, técnicas, sociais, econômicas e financeiras, em âmbito nacional e internacional e nos diferentes modelos de organização. O egresso deve apresentar pleno domínio das responsabilidades funcionais envolvendo apurações, auditorias, perícias, arbitragens, noções de atividades atuariais e de quantificações de informações financeiras, patrimoniais e governamentais, com a plena utilização de inovações tecnológicas. Além disso, revelar capacidade crítico-analítica de avaliação, quanto às implicações organizacionais com o advento da tecnologia da informação.

O Projeto Pedagógico (PP) de um curso de graduação é o instrumento que expressa em seu conteúdo a prática pedagógica das instituições e dos cursos, dando um norte à gestão e às atividades educacionais (BAFFI, 2003). Diante disso, o Projeto Pedagógico do Curso de Ciências Contábeis da Universidade de Caxias do Sul (UCS, 2010) apresenta, entre outros, como um dos seus objetivos específicos "viabilizar ações que estimulem o espírito empreendedor" (UCS, 2010, p.5). Diante disso, possui em seu plano de organização curricular a disciplina de empreendedorismo, que visa "proporcionar ao aluno situações para que ele possa definir as principais características do comportamento do profissional empreendedor e desenvolver estratégias para análise de riscos e identificação de oportunidades de um novo empreendimento" (UCS, 2010, p.94).

Este enfoque exige que o corpo docente empregue diferentes metodologias de ensino. Se o objetivo é proporcionar aos alunos informações sobre processo de criação de empresas e valores e atitudes que precisam direcionar a prática empresarial, as aulas expositivas e as 
leituras obrigatórias são as mais recomendadas. No entanto, caso o foco esteja em desenvolver comportamentos empreendedores, as estratégias que permitam reflexão sobre o próprio comportamento são as mais adequadas. Já para identificar e avaliar oportunidades, a metodologia de desenvolvimento de projetos é a técnica de ensino que pode vir a surtir maior efeito. A escolha entre as opções de técnicas pedagógicas deve ser feita sob o pressuposto de que educação empreendedora deve se centrar no desenvolvimento de habilidades que facilitem a tomada de decisões, as quais englobariam capacidade de inovar, assumir riscos e resolver problemas (GUIMARÃES, 2002).

\section{Aspectos Metodológicos}

Quanto aos objetivos, trata-se de uma pesquisa descritiva. De acordo com Sampieri, Collado e Lucio (1991), os estudos descritivos são utilizados quando o pesquisador tem o objetivo de medir aspectos, dimensões ou componentes de determinado fenômeno que seja submetido à análise. Segundo Cervo, Bervian e Silva (2007) os dados necessitam ser coletados e registrados ordenadamente para seu estudo propriamente dito.

Já em relação aos procedimentos, foi utilizada uma survey. May (2004) afirma que a survey se caracteriza pela coleta de dados referentes a um grande número de pessoas, e visam descrever ou explicar as características de uma população através da utilização de uma amostra representativa.

Em relação a abordagem, este estudo contempla as características de uma pesquisa quantitativa e qualitativa. Oliveira (2011) diz que estes dois métodos, embora diferentes, não são excludentes, pois "podem ser usados em conjunto e de forma complementar numa mesma pesquisa" (p.80). De acordo com o mesmo autor, estudos com metodologia qualitativa podem descrever a complexidade de determinado problema, além de analisar a interação de suas variáveis. Quantitativa, pois a metodologia desenvolvida, traduz em números as opiniões coletadas, para classificá-las e analisá-las neste sentido Richardson (1989) comenta que, o método quantitativo emprega um instrumental estatístico como base do processo de análise do problema, objetivando medir unidades ou categorias homogêneas.

Esta pesquisa foi direcionada aos formandos do curso de Ciências Contábeis da Universidade de Caxias do Sul, na Cidade Universitária (Campus Sede). De acordo com os registros acadêmicos, o total de formandos no ano é de 100 alunos. Os questionários foram distribuídos basicamente de duas formas: aos alunos que se formaram no primeiro semestre do ano foram enviados os questionários via e-mail, sendo solicitado que estes o devolvessem 
preenchido, também via e-mail; para aqueles que concluem o curso no segundo semestre, os questionários foram entregues pessoalmente, e recolhidos após o preenchimento.

A escolha da instituição e dos pesquisados observou os critérios de viabilidade de acesso aos respondentes e concordância em participar da pesquisa. Do total de questionários distribuídos retornaram 36, o que equivale a uma amostra de $36 \%$ da população alvo.

\section{Resultados da pesquisa}

Para atingir os resultados esperados, de acordo com o objetivo proposto para o presente estudo, foi utilizado questionário proposto e validado por Demac (1990). O questionário é caracterizado como um teste de múltipla escolha, contendo 26 questões, sendo que cada uma delas possui entre duas e seis opções. As respostas são pontuadas conforme uma tabela específica, e o resultado final é calculado conforme Figura 1.

Figura 1: Pontuação para análise dos resultados

\begin{tabular}{|rl|}
\hline Pontos & Perfil \\
\hline $\mathbf{2 3 5 - 2 8 5}$ & A -Empreendedor com êxito. Pode iniciar várias empresas e obter êxito. \\
\hline $\mathbf{2 0 0 - 2 3 4}$ & B - Empreendedor. Pode iniciar uma empresa com êxito. \\
\hline $\mathbf{1 8 5 - 1 9 9}$ & C -Empreendedor latente. Tem vontade de iniciar uma empresa. \\
\hline $\mathbf{1 7 0 - 1 8 4}$ & D - Empreendedor potencial. Tem habilidades, mas ainda não pensou em iniciar \\
\hline $\mathbf{1 5 5 - 1 6 9}$ & E -Empreendedor incipiente. Necessita treinamento para ter êxito. \\
\hline
\end{tabular}

Fonte: Adaptado de Demac (1990)

As respostas foram tabuladas e utilizadas fórmulas que apresentam os valores de cada uma das opções marcadas, bem como, fazem o somatório total de cada um dos questionários. De acordo com o questionário utilizado, se a pontuação não ultrapassar 154 pontos indica que o respondente não tem perfil empreendedor. No entanto se o valor apurado ficar entre 155 e 285, que é a pontuação máxima possível, o respondente será classificado de acordo com as faixas apresentadas na figura 1.

\subsection{A tabulação dos questionários respondidos}

A partir dos procedimentos descritos no tópico anterior, os resultados dos questionários foram tabulados e compilados. Verificando o perfil dos respondentes, é perceptível que a grande maioria dos pesquisados (61\%) não pode ser classificada como empreendedor, pois não atingiu o somatório de 155 pontos. A Figura 2 apresenta, em termos percentuais, o perfil empreendedor identificado nas respostas dos questionários. 
Aproximadamente um terço dos pesquisados se enquadra no Perfil E, que, de acordo com a literatura, são empreendedores incipientes, que necessitam de treinamento para terem sucesso.

Figura 2: Perfil empreendedor dos respondentes

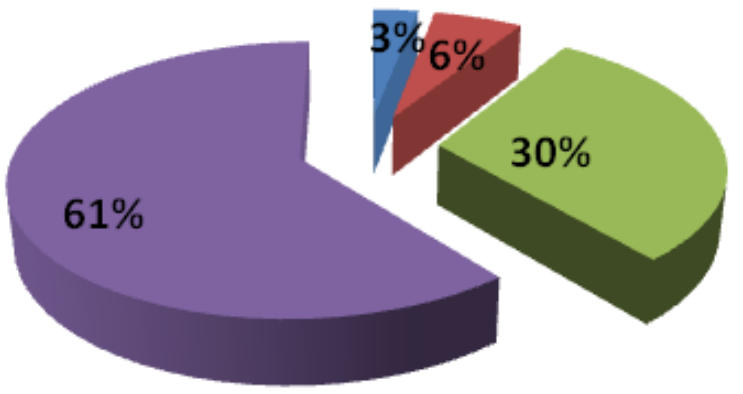

\section{Perfil C Perfil D Perfil E $\square$ Não é empreendedor}

Fonte: Dados da pesquisa.

Aproximadamente 6\% dos respondentes se enquadram no Perfil D. Esse perfil pode ser caracterizado por pessoas que são empreendedoras em potencial, mas que ainda não pensaram em abrir uma empresa. Apenas 3\% dos indivíduos pesquisados se enquadram no Perfil C, o qual a literatura relacionada chama de empreendedor latente, ou seja, tem vontade de iniciar uma empresa. O que chama mais atenção é que nenhum dos pesquisados se encaixa no Perfil A ou B. De acordo com Demac (1990), o indivíduo que se encaixa em qualquer um desses dois perfis é empreendedor, e pode iniciar uma ou mais empresas com êxito.

\subsection{Análise e interpretação dos resultados}

A amostra é composta, na sua maioria, de pessoas que ainda não foram demitidas de nenhum emprego, cuja família toda nasceu no Brasil, trabalha ou trabalhou principalmente em empresas de até 100 empregados. Além disso, são indivíduos que nunca administraram uma empresa antes dos 20 anos de idade, tem entre 21 e 30 anos de idade, não é o filho mais velho da família, e é solteiro.

Os resultados da pesquisa indicam que quase dois terços $(61 \%)$ dos entrevistados não tem perfil empreendedor, pois não atingiram 155 pontos no somatório das respostas dos seus questionários. Analisando as repostas do questionário de maneira mais específica, apresentam-se alguns dados que merecem destaque. Algumas questões que tem pontuação 
maior, com opções que valem até 15 , pontos foram analisadas uma a uma, quais sejam: Q7, Q10, Q17, Q19, Q21 e Q26 os resultados serão analisados a seguir.

A Q7 diz respeito a posição do indivíduo dentro da família sendo a resposta com 15 pontos a do primogênito. Entre os respondentes $42 \%$ marcaram a opção de primogênito. Além disso, 44\% marcaram a opção de mais jovem ou filho adotivo, o que equivale a zero pontos. Os $14 \%$ restantes marcaram a opção de irmão do meio, que vale 2 pontos. Em função dessas considerações, pela posição que ocupa na família praticamente metade dos respondentes não é o primogênito que segundo o questionário é a posição com maior índice para um perfil empreendedor. Segundo Hisrich (2004 p. 47-48) “o empreendedor geralmente é o filho mais velho da família".

Já na Q10 que pergunta qual o motivo principal que impulsiona o indivíduo a criar uma empresa, entre os entrevistados $72 \%$ responderam que trabalhar de forma independente seria o motivo, sendo a opção que vale 15 pontos. Os demais entrevistados $28 \%$ responderam entre as opções de dinheiro, sentir-se importante e dar saída a sua energia que valem zero ponto cada uma. Neste aspecto a grande maioria respondeu conforme o perfil empreendedor. Conforme Hisrich (2004, p. 47-48) “a principal motivação do empreendedor para iniciar um negócio é ser independente. A necessidade de independência (a incapacidade de trabalhar para outra pessoa) é o que impulsiona o empreendedor a correr riscos e trabalhar todas as horas necessárias para criar um empreendimento".

Na Q17 estima-se qual a situação que convenceria mais rapidamente o indivíduo, se ele tivesse uma empresa. A questão traz cinco alternativas, a opção cuja maior pontuação, diz respeito a todos os itens apontados. Dos pesquisados, 39\% responderam nesta opção valendo 15 pontos. Os demais responderam entre as opções de novas idéias de produtos, novos empregados novas ideias de manufatura, novos programas financeiros valendo cinco pontos cada uma. "O empreendedor é a personalidade criativa; sempre lidando melhor com o desconhecido, perscrutando o futuro, transformando possibilidades em probabilidades, caos em harmonia" (GERBER, 1996 p. 31).

A Q19 avalia a razão do trabalho do respondente ser melhor que o dos demais. Entre os entrevistados apenas $14 \%$ responderam sempre organizar bem seus assuntos, esta alternativa tem a maior pontuação, vale 15 pontos. Os demais respondentes $86 \%$, marcaram entre as duas outras opções que são: gostar de cumprir com seus compromissos e estar acostumado a sair adiante, que valem 5 pontos cada.

Já na Q21 que, questiona a preferência em lidar com o risco. Dos respondentes, 92\% preferem trabalhar em um problema com 1 oportunidade sobre 3 de resolvê-lo no prazo 
previsto, esta opção é a que vale 15 pontos. E $8 \%$ responderam preferir jogar um dado com 1 oportunidade sobre 3 de ganhar, questão que vale zero ponto.

Na Q26 apresenta o que mais preocupa o entrevistado em uma competição. Dos respondentes $11 \%$ marcaram a opção de ganhar ou perder valendo 10 pontos, $44 \%$ optaram pela opção: a forma como joga, valendo 8 pontos, $42 \%$ marcaram a opção de ambas (forma como joga e ganhar ou perder), valendo 15 pontos. $3 \%$, ou seja, um respondente marcou a opção nenhuma, isso quer dizer, que nenhuma das duas opções o preocupa.

Merece destaque que a maior parte das respostas teve pontuação zerada, ou seja, o respondente não obteve nenhuma pontuação. A Q3, por exemplo, teve $86 \%$ de respostas na alternativa "Os avós, os pais e você nasceram todos no Brasil", esta não tem pontuação no questionário. $\mathrm{Na}$ Q5, 92\% dos respondentes tiveram zero pontos, pois responderam não ter administrado nenhuma empresa antes dos 20 anos como por exemplo uma oficina. Segundo Hisrich (2004) é muito importante a experiência administrativa e empresarial na medida em que aumenta a complexidade do empreendimento.

A Q15 teve $89 \%$ de respostas com pontuação zerada. A questão pergunta qual o fator que o entrevistado considera ao mesmo tempo necessário e suficiente para empreender um negócio, apenas uma das alternativas é que pontuava, cuja resposta era "clientes", e os respondentes que não marcaram pontos, marcaram entre as opções de "dinheiro", "uma idéia ou produto" e "motivação e trabalho duro". Conforme afirma Hisrich (2004 p. 84) "os clientes ou compradores são um grupo particularmente importante a cultivar. Esse grupo representa a fonte de ganhos do empreendimento e é o melhor provedor de propaganda boca a boca. Não há nada melhor do que a propaganda feita por clientes satisfeitos para ajudar a estabelecer a reputação de um negócio vitorioso e promover a boa vontade".

$\mathrm{Na}$ Q22 exatamente $83 \%$ dos entrevistados zeraram sua pontuação respondendo à questão: "Qual das seguintes profissões escolheria, se dependesse de você: a resposta que valia mais pontos (10 pontos) é vendas, não foi escolhida em nenhum questionário. A resposta com pontuação três (3) esportista profissional, foi assinalada por seis entrevistados. E as respostas que não valiam pontos onde a maioria assinalou são: "consultoria empresarial" e “ensino". Para Dolabela (1999, p.72-74) a "atividade de vendas que o empreendedor desenvolve para atingir seus objetivos está vinculada à característica pessoal de flexibilidade para ajustar-se aos clientes, buscar feedback, e exige a competência de adaptar-se às pessoas e circunstâncias". 


\section{Conclusão}

A partir do presente estudo, é possível afirmar que o empreendedorismo é essencial para uma nação, pois é dele que surgem as novas empresas. Essa afirmação é sustentada na revisão da literatura realizada, na qual os autores têm consenso em sustentar uma necessidade de ativação do perfil empreendedor nos indivíduos. Segundo os autores, é a partir de ideias empreendedoras que surgirão inúmeras pequenas empresas, que, se geridas adequadamente, poderão se transformar em grandes empresas no futuro.

A educação formal, principalmente os cursos de graduação, são elementos fundamentais no processo de formação desses empreendedores. Independente da área de estudos escolhida pelo indivíduo, os cursos devem contribuir de alguma forma na formação do futuro empreendedor. Os alunos da área de Ciências Contábeis, em especial, têm no currículo do curso várias disciplinas que oferecem subsídios teóricos e práticos para gerir adequadamente uma empresa. Além disso, é cada vez maior no Brasil a inclusão da disciplina de empreendedorismo na grade curricular desse curso.

Diante desse contexto, o objetivo da presente pesquisa estudo foi analisar o perfil empreendedor dos egressos do curso de contábeis de uma instituição de ensino superior privada. Para a realização da pesquisa foram distribuídos questionários aos alunos formandos do ano 2014 no referido curso. Do total de questionários distribuídos, retornaram 36\%, e esta amostra é composta na sua maioria de pessoas que ainda não foram demitidas de nenhum emprego, cuja família toda nasceu no Brasil, trabalha ou trabalhou principalmente em empresas de até 100 empregados. A amostra aponta também que os respondentes são pessoas que nunca administraram uma empresa antes dos 20 anos de idade, têm entre 21 e 30 anos de idade, não é o filho mais velho da família, e são solteiros.

A partir da análise dos dados da amostra, verificou-se que $61 \%$ dos respondentes não podem ser classificados como empreendedores, pois, de acordo com as pontuações das respostas dos questionários, não atingiu o somatório mínimo para ser classificado como tal. $\mathrm{O}$ restante dos pesquisados foi classificado como "empreendedor incipiente", cujo grupo é caracterizado por pessoas que necessitam ter treinamento para ter êxito (30\%), "empreendedor potencial", ou seja, têm habilidades, mas ainda não pensaram em iniciar uma empresa (6\%), e "empreendedor latente", que tem vontade de abrir uma empresa (3\%). Chama atenção o fato de que nenhum dos pesquisados ser, de fato, empreendedor, pois as pontuações obtidas nos questionários não foram suficientemente altas para tal enquadramento. 
Uma limitação deste estudo é o baixo retorno dos respondentes, visto que retornaram pouco mais de um terço de questionários respondidos. Além disso, é possível que, como foram entrevistados apenas os concluintes de um determinado ano, exista um viés de baixo empreendedorismo apenas nos alunos desse ano. Assim, para estudos futuros, sugere-se que sejam analisados e comparados os concluintes de diferentes anos, ou a variação do perfil empreendedor evolução entre os ingressantes e concluintes do curso. Outra sugestão seria a realização de uma análise comparativa do perfil empreendedor entre diferentes cursos, de diferentes instituições de ensino.

\section{Referências Bibliográficas}

BAE, T. J.; QIAN, S.; MIAO, C.; FIET, J. O. The Relationship Between Entrepreneurship Education and Entrepreneurial Intentions: A Meta-Analytic Review. Entrepreneurship Theory and Practice, v. 38, n. 2, p. 217-254, 2014.

BAFFI, M. A. T. Projeto Pedagógico: um estudo introdutório. Pedagogia em Foco. Petrópolis, 2003.2 Disponível em: http://www.portal.santos.sp.gov.br/seduc/e107_files/downloads/ Acesso em: 16 out. 2015.

BOLTON, W. K.; THOMPSON, J. L. Entrepreneurs: talent, temperament, technique. Butterworth Heinemann: Oxford, 2000.

BRUYAT, C; JULIEN, P. A. Definind the field of research in entrepreneurship. Journal of Business Venturing, v. 16, n. 2, p. 165-180, 2000.

BYGRAVE, W. D. The entrepreneurial process. In W. D. Bygrave \& A. Zacharakis (Eds.). The portable MBA in entrepreneurship. Hoboken, NJ: John Wiley \& Sons, 2004.

CATELLI, Armando. Controladoria: uma abordagem da gestão econômica. 2 ed. São Paulo: Atlas, 2001.

CERVO, Amado Luiz. BERVIAN, Pedro Alcino. SILVA, Roberto da. Metodologia Científica. 6.ed. São Paulo: Pearson Prentice Hall, 2007.

CUNHA, Roberto de Araujo Nascimento; STEINER NETO, Pedro José. Desenvolvendo Empreendedores: o desafio da Universidade do século XXI. In: XI Seminário LatinoIberoamericano de Gestión Tecnológica. Salvador: 2005.

DEGEORGE, Jean-Michel. FAYOLLE, Alain. The entrepreneurial process trigger: a modelling attempt in the French context. Journal of Small Business and Enterprise Development. v. 18 n. 2, p. 251-277, 2011.

DEMAC - Desarollo Empresarial de Monterrey, A.C. Conviertase en emprendedor. Instituto Tecnológico y de Estudios Superiores de Monterrey. Em: Programa de impacto a la Comunidad: conviertase en emprendedor, Instituto Tecnológico y de Estudios Superiores de Monterrey. Monterrey: Personal, 1990.

DOLABELA, Fernando. Oficina do empreendedor. São Paulo: Cultura Editores Associados, 1999.

DORNELAS, J. C. A. Só coragem não basta: para buscar oportunidades as pessoas não precisam ter um dom especial. Revista Forbes, 26 de Abril de 2002. 
DRUCKER, Peter Ferdinand. Inovação e Espirito Empreendedor. 1. ed. São Paulo: Thompson Pioneira, 1986.

ECKERT, Alex. Teoria da Contabilidade para o Exame de Suficiência do CFC. 2. ed. São Paulo: Edipro, 2013.

FILION, Louis Jacques. Empreendedorismo: empreendedores e proprietários-gerentes de pequenos negócios. Revista de Administração da USP - RAUSP, v.34, n.2, p.5-28, 1999.

GEM - Global Entrepreneurship Monitor: GEM Global Report. 2010. Disponível em: http://www.gemconsortium.org/download/1321576365031/GEM\%20GLOBAL\%20REPORT \%202010rev.pdf. Acesso em: 10 dez. 2011

GERBER, Michael E. O Mito do Empreendedor revisitado:como fazer de seu empreendimento um negócio bem sucedido. São Paulo: Saraiva, 1996.

GLAESER, Edward L.; KERR, Sari Pekkala; KERR, William R. Entrepreneurship and urban growth: An empirical assessment with historical mines. Review of Economics and Statistics, v. 97, n. 2, p. 498-520, 2015.

GUIMARÃES, L. O. Empreendedorismo no Currículo dos Cursos de Graduação e Pósgraduação em Administração: análise da organização didático-pedagógica destas disciplinas em escolas de negócios norte-americanas. In: XXVI ENCONTRO ANUAL DA ANPAD, 2002, Salvador. Anais Eletrônico. Salvador: ANPAD, 2002.

HISRICH, Robert D.; PETERS, Michael P. Empreendedorismo. 5. ed. Porto Alegre: Bookman, 2004.

HONG, Yuh Ching. Contabilidade gerencial. São Paulo: Pearson Prentice Hall, 2009.

IEL - Instituto Euvaldo Lodi. Empreendedorismo: ciência, técnica e arte. Brasília: CNI. IEL Nacional, 2000.

INÁCIO JR., E.; GIMENEZ, F.A.P. Potencial Empreendedor: um instrumento para mensuração. In: XXII SIMPÓSIO DE GESTÃO DA INOVAÇÃO TECNOLÓGICA, Salvador, 2002. Anais.

IUDÍCIBUS, Sérgio de. Contabilidade Gerencial. 6. ed. São Paulo: Atlas, 1998.

IUDÍCIBUS, Sérgio de; MARION, José Carlos. Introdução à teoria da contabilidade para o nível de graduação. São Paulo: Atlas, 1999.

KUMAR, Sushil. ALI, Jabir. Indian agri-seed industry: understanding the entrepreneurial process. Journal of Small Business and Enterprise Development. v. 17, n. 3, p. 455-474, 2010.

LEITE, Roberto C. De executivo a empresário: como realizar o seu ideal de segurança e independência. Rio de Janeiro: Campus, 1998.

MAY, Tim. Pesquisa Social: questões, métodos e processos. Trad. SOARES, Carlos Alberto Silveira Netto. 3.ed. Porto Alegre: Artmed, 2004.

OLIVEIRA, Antonio Benedito Silva. Métodos da Pesquisa Contábil. São Paulo: Atlas, 2011.

PADOZEVE, Clóvis Luís. Controladoria estratégica operacional: conceitos, estrutura, aplicação. 2 ed. São Paulo: Cengage Learning, 2009.

PEREZ JR., José Hernandez; PESTANA, Armando Oliveira; FRANCO, Sergio Paulo Cintra. Controladoria de Gestão: teoria e prática. 2 ed. São Paulo: Atlas, 1995. 
RESOLUÇÃO CNE/CES 10, DE 16 DE DEZEMBRO DE 2004. Diretrizes Curriculares Nacionais para o Curso de Graduação em Ciências Contábeis. Disponível em: http://portal.mec.gov.br/cne/arquivos/pdf/rces10_04.pdf. Acesso em: 05/12/2011.

RIBEIRO, Osni Moura. Contabilidade Básica. São Paulo: Saraiva, 2005.

RICHARDSON, R. J. Pesquisa Social: métodos e técnicas. São Paulo: Atlas, 1989.

SÁ, Antonio Lopes de. Fundamentos da Contabilidade Geral. 2. ed. Curitiba: Juruá, 2007

SAMPIERI, Roberto Hernández; COLLADO, Carlos Fernández; LUCIO; Pilar Batista. Metodología de la Investigación. Ciudad Del México: McGraw-Hill, 1991.

SCHUMPETER, Joseph Alois. Teoria do desenvolvimento econômico: uma investigação sobre lucros, capital, crédito juro e o ciclo econômico. São Paulo: Abril, 1982.

SEBRAE - Serviço Brasileiro de Apoio às Micro e Pequenas Empresas. Doze Anos de Monitoramento da Sobrevivência e mortalidade de empresas. 2011. Disponível em: www.sebraesp.com.br/TenhoUmaEmpresa/Biblioteca/OutrosConteudos/EstudosEPesquisas/ MortalidadeDasEmpresas/Paginas/MortalidadeDasEmpresas.aspx\#bottom. Acessado em: 03 nov. 2011.

STEVENSON, H. H. O compromisso é conseguir. HSM Management, n. 25, ano 5, p. 7276, 2001.

TIMMONS, Jeffry A. New Venture Creation. 4. ed. Boston: Irwin. Mc Graw-Hill, 1994.

UCS - Universidade de Caxias do Sul - Projeto Pedagógico do Curso de Ciências Contábeis. CD-ROM, 2010. 